\title{
The principles of inference in discourse comprehension
}

\author{
Elena Suvorova
}

DOI: 10.18355/XL.2020.13.02.06

\begin{abstract}
A substantial research has been undertaken to reveal the principles of inference in the course of discourse comprehension. The research bases upon a new approach to the inference as a dynamic, changeable, ecologically compatible phenomenon which involves not only the processing of semantic content of linguistic units comprising the discourse, but also depends upon, firstly, a human being as "a receiver", who is capable of highlighting some part of semantic content and downplaying the other, thus, arbitrarily changing the focus of comprehension, and, secondly, a communicative situation, which interferes into a comprehender's subjective selection of the most relevant semantic data to be included in the inference and, thus, either supports or, vice versa, interferes and transforms the senses intended in the discourse. An important emphasis is made on the anthropocentric nature of inference and its close link to the cognitive restoration of the environment hidden in the discourse. The virtual environment indirectly influences the discourse comprehension and makes an impact on the inference. The action of the identified inferential principles is illustrated on the examples of understanding of some short dialogues and pieces of literary writings and has been verified by an associative experiment that builds upon the subjects' written, sensory and graphical feedback in the course of comprehending three small pieces of discourse.
\end{abstract}

Key words: anthropocentrism, comprehension, discourse, inference, principle, reasoning

\section{Introduction}

Nowadays, in the framework of the discourse comprehension problem, there is a lot of discussions, devoted to the search for an answer to the question: "How and why in the course of comprehension do separate linguistic elements become cognitively fused into an entity having much more semantic sense than the semantic content of all these elements taken together?" Inference study might throw light on this scientific puzzle, as these are the inference mechanisms and regularities that lie in the heart of the semantic metamorphosis. The inference is a result and a process of cognitive treatment of the limited, but dynamically changing and, to some extent a chaotic number of perceived linguistic and extra-linguistic senses, in the course of which new knowledge appears, enriched by personal senses, evaluations, and emotions. As a consequence, the identification of the main mechanisms of inference, the reveal of the nature, structure, and content of the inferred knowledge, the development of the common view on the dependence of the inferred knowledge from the linguistic and extra-linguistic factors, and the identification of the principles of the inference action itself are the pieces of the abovementioned puzzle, which needs a solution. Nevertheless, the vagueness, subjectivity, fragmentation of the existing knowledge about the inference phenomenon, the interpretation of the inference only as a mechanism of text perception, and, as a consequence, lack of attention to the anthropocentric essence of inference, the disregard of such important features of the inference as dynamism and changeability do not allow articulating a uniform objective picture of this dimensional phenomenon, simultaneously related to language, cognition, and reasoning. Hence, the main purpose of the paper is to study the inference as a phenomenon related simultaneously to both the cognition and discourse; to reveal and characterize the main principles of its action. The reveal of 
the principles will allow getting inside the nature of the inference phenomenon and identifying its possible mechanisms of action.

To reach the purpose, firstly, we make a review of the theoretical and practical philosophic, psychological, and linguistic literature on the cognition, reasoning, and inference; secondly, give phenomenological characteristics of the probabilistic principles of inference and describe their action in a comprehension process; thirdly, verify the revealed principles by means of an associative experiment in order to illustrate the work of the principles while comprehending a piece of narrative discourse. Short dialogues, some small text passages from literary writings as well as an empirical observation of the common human communication serve as the material for the theoretical analysis and the description of the essence of the principles. At the same time, an associative experiment verifies the proposed hypothesis and illustrates the action of the principles when drawing inferences under the conditions of real discourse comprehension. The methods used in a theoretical part of the conducted research are the method of analysis and synthesis of theoretical and practical literature on the inference problem; a discourse-analysis of the passages taken from original fiction literature, which implies the analysis of the probabilistic variants of semantic inferences, regarding the linguistic and extra-linguistic content of the comprehended material.

\section{The theoretical analysis of philosophic, psychological and linguistic literature on the problem of principles of reasoning}

The tries to identify inference principles have resulted in the necessity to address to human reasoning as a process, including inference as one of the forms of this reasoning. Philosophy has always been the starting point and the basis of other sciences' development, thus, the first philosophic work, which mentions and defines a principle, is the essay "About nature" written by Anaximander, who characterizes it as the heart of the matter (Asmus, 1998). Besides Anaximander's works, the philosophic reflection about the essence of a principle can be found in the works of Aristotle (a principle is a root cause of everything), Descartes (a principle is a self-evident basis for any reasoning and cognition (Philosophical writings of Descartes, 2012), and Kant (a principle is a set of constructive and regulative rules of Pure Reason (Philosophical writings by Immanuel Kant, 1997). Nevertheless, the necessity to study the notion "principle" in the frameworks of cognition and discourse comprehension has confined its philosophic understanding to the idea (based on the integration of Descartes and Kant's reflection) that a principle is a certain cognitive law regulating thinking process.

Reviewing psychological and linguistic literature on reasoning, we proceed from the assumption that language and thought are inseparable and that thinking rests upon inner speech, enriched by images, schemas, emotions, etc. (Vygotskey, 2019). In the psychological literature, the descriptions of principles of reasoning are rarely met, and in these few cases, they are closely connected with the logic laws. In considering the reflective thinking, Dewey (1933) proceeds from the main characteristics of thinking, which can be referred to the principles of induction and deduction; analysis and synthesis; the periodical shift between apprehension and comprehension (which are considered to be direct and indirect ways of comprehension correspondingly). In its turn, the process of thinking or reflection consists of five distinct logical steps: "a felt difficulty, then, its location and definition, later a suggestion of possible solution; then, the development by the reasoning of the bearings of the suggestion, and finally, some further observation leading to its acceptance or rejection, i.e., the conclusion of belief or disbelief" (Dewey, 1933, p.71). Another psychological study completely replaces the laws of thinking by the Aristotle's syllogisms, thus, neglecting such

XLinguae, Volume 13 Issue 2, April 2020, ISSN 1337-8384, ISSN 2453-711X 
features of reasoning as creativity, dynamism, ecological compatibility (i.e., dependence on the environment, the speaker and the object of the thinking process) (Korotkov, 2011). There is also one more similar theory which considers most of the human thought to be based on such principles underlying language as causal primacy ("when $\mathrm{x}$ happens, $\mathrm{y}$ happens" is construed as "x causes $\mathrm{y}$ to happen") and identification (any event is interpreted as an action with a causal agent) (Bickerton, 1995). Obviously, the laws of formal logic can be applied to thinking, but only to one type of it - rational thinking (Emets, Baryshnikova, Trutnev, Suvorova, Achmetzyanova, 2018).

In this regard, it should be noted that there are also a few significant works that articulate their own original approaches to the process of thinking (most of them focus on some special kind of thinking - a figurative one). In the book "Metaphors we live by" thinking \ reasoning (we do not differentiate between these two terms) is associated with a conceptual mapping, metaphoric or metonymic cognitive interpretation of one conceptual domain in terms of another (Lakoff, Johnson, 2008). In this way, metaphor becomes a cognitive, not merely linguistic, activity. There is also a similar approach associating reasoning with a conceptual blending, where "a structure is selectively projected from "input" mental spaces to a "blended" space that also develops its own emergent structure" (Fauconnier \& Turner, 2002). These works propose a view on reasoning as a whole process but help little in articulating the principles (rules, laws) that frame and regulate the processes/mechanisms of thinking.

A brief analysis of the principles of thinking regarding philosophic, psychological and linguistic approaches shows that in spite of the fact that inference is a form of thinking and should be considered in the framework of its description (logic), it cannot comply with the common logical ways of thinking, because inference does not depend on any primary assumptions and can transform under the influence of indirect, peripheral factors sometimes having extra-linguistic character (e.g., prosody; emotions that are implied in the utterance; disbalance between the speech situation and the utterance, and so on). Consequently, to reveal the nature of inference, it is necessary to find other principles than those that characterize the thinking process as a whole.

The review of the linguistic literature shows that the problem of identification and description of the inference principles remains insufficiently studied in this field. One of a few works mentioning inference principles is "Discourse analysis" of G. Brown and G. Yule discussed below (Brown, Yule, 1983). The lack of study of the inference principles makes an address to the works describing the inference phenomenon in general. In pragmatics, the study of the process of inferring implicit information is closely connected with the semantic theory of P. Grice, who is the first to introduce the technical term "implicature" (the process of implication) and its cognates "to implicate" and "implicatum" (i.e., that which is implicated) (Grice, 2001). Later on, the concept of inferred semantic knowledge is tightly associated with such notions as syllogism, deduction, implicature, presupposition, and inference (Odintsova, 2016). These notions overlap in many ways, but, nevertheless, characterize different sides of the inferred semantic knowledge. In particular, the term syllogism (deduction), suggested by Aristotle, means a conclusion made on four (sometimes five) differentiae: (i) there are at least two premises which are posited; (ii) the conclusion is different from the premises; (iii) the conclusion follows necessarily from the premises; (iv) the premises imply the conclusion by themselves; they are jointly necessary and sufficient for the conclusion to be produced (Aristotel,1984). In other words, a syllogism is a form of logical reasoning that joins two or more premises to arrive at a conclusion. For example: "All birds lay eggs. A swan is a bird. Therefore, a swan lays eggs." But this kind of logic is scarcely compatible with every day speech, that is full of implicit senses, colloquial expressions, understatement, 
grammar and stylistic irregularities, that is why, a syllogism or a deduction is generally an inappropriate word to characterize the mechanism of a semantic inference, based upon a dynamic, changeable system of linguistic and extra linguistic data (Suvorova, Polyakova, 2018) being processed in the course of speech comprehension. Nevertheless, an inference can have formal logic nature, provided its result is an objective and precise conclusion made on true to life facts or premises. In this connection, Makarov (2003) considers two types of inference: (i) a formal, logical inference based upon true premises and (ii) a probabilistic, inductive inference having a pragmatic character and including guesses, associations, reflecting the communicative situation, emotions, and common knowledge. The terms inference and implicature are not interchangeable too. Some researchers consider implicature as a formal bridge between propositions which appear in the course of discourse formation and comprehension (Zavarzina, 2016). This approach allows comparing implicature with a bridging or gap-filling inference (Rickheit \& Strohner, 1985); nevertheless, the main difference between the notions is in the way of their action. If implicature is related to the terms of the formal logic and implies a direct logical approach to the inferred semantic knowledge, the inference should be considered as an arbitrary conclusion based upon the processing of some semantic content in parallel with personal, situational, contextual extra-linguistic data.

To sum up, the inference is an inner, mostly unconscious process of getting inferred knowledge, with the use of guess, intuition, personal experience, and based upon contextual, situational, dynamic and changeable extra-linguistic information. It becomes obvious that the reviewed principles of reasoning often replaced by logic laws are inappropriate to characterize the inference action, and, as a consequence, there is a need to search for other principles, which might completely characterize the inference nature.

\section{Principles of inference when comprehending a narrative discourse}

According to the Oxford Dictionary, the word principle has several meanings: 1) a fundamental truth or proposition that serves as the foundation for a system of belief or behavior or for a chain of reasoning; 2) a general scientific theorem or law that has numerous special applications across a wide field; 3 ) a fundamental source or basis of something (2005). But above all, the inference is a cognitive process, arising from a human being's exceptional capabilities. Hence, the process is primarily implemented in those spheres which characterize human behavior: biology, physics, chemistry, physiology, linguistics, sociology, etc. interconnected on the platform of philosophy. According to the Philosophical Dictionary, a principle is an initial phase, leading idea, a major rule of behavior, expression of necessity, or law regulating phenomena (1981). In logic, a principle is a central notion, a system foundation, which is generalized and applied to all the phenomena in the sphere from which it is abstracted (Korotkov, 2011). As a consequence, inference principles are the rules which accompany the whole process of coming to a cognitive conclusion, which rests upon the human ability to process the internal and internal dynamic information simultaneously, often unconsciously, illogically relying upon arbitrary peripheral factors (such as the interlocutor's intonation, mimics, his \her well-being, the speech situation, etc.).

As it has been mentioned before, one of the few works describing principles of inference is the study carried out by Brown and Yule (1983). They describe the inferential principles of local interpretation and analogy. The principle of local interpretation instructs the reader not to construct a situational or conversational context any larger than he needs to arrive at an interpretation (Brown, Yule, 1983, p.59). In particular, analyzing the following dialogue between a mother and a child:

XLinguae, Volume 13 Issue 2, April 2020, ISSN 1337-8384, ISSN 2453-711X 
Mother: Is the father in?

Child: No, he is out (the example is taken from a real family communication), one can see that the child understands that the focus of the conversation is on his own father. Though Brown and Yule think that it is the knowledge of the world that constraints the local interpretation (Brown, Yule, 1983, p.61), it is more natural to think that it is the conversational and situational context accompanied by one's own life experience that really influences our comprehension (for example, the same answer will be made in the dialogue which takes place between a visitor and a child who has no father but has an elder brother. In this situation, the child will infer that the visitor implies his sibling). Thus, the principle is better to be called a principle of situational (conversational) economy, because the speaker does not construct a context, but chooses a shortcut to achieve understanding, picking up the only sustainable (to his mind and at the precise moment) detail that will lead him to the possibly appropriate conclusion - the visitor speaks about his brother. But imagine another situation - a child feels ill, and a random visitor asking him about his father can trigger the same answer but an absolutely different inference:

Visitor: Is the father in (Is there an adult at home to help)?

Child: No, he is out,

implying that nobody can help. (Thus, another detail becomes "the first violin" and in this role interferes into the inference. It is the child's state of health).

The principle of analogy implies that the interpretation of the text would more likely rest upon addressee's personal experience than on any encyclopedic knowledge. When we are asked a puzzle, we firstly start seeking for an answer in our experience, but not in the encyclopedic knowledge. For instance, some answers to the puzzle "clean, but not water, white, but not snow, sweet, but not ice-cream. What is it?" can be "cream," "sugar," "lemonade, "and so on. A similar example is taken from teachers' practice. When several little Russian children are asked to draw a picture illustrating a verse from Pushkin's poem "Evgeney Onegin": And now the dashing kibitka (an old Russian carriage) flies in the powdery snow, (they are not familiar with the word kibitka), they draw a flying machine, as they rely upon the word fly and their own experience of flights and flying machines (Suvorova, 2019).

The next couple of principles are the principles of cohesion and coherence, which reflect the continuity and integrity of a semantic conclusion. Though being different from ordinary human speech, inference preserves its features: cohesion and coherence (due to the tight connection between reasoning and inner speech). Besides the processed semantic content of linguistic units, the conclusion always involves a certain array of extra-linguistic data, and, that is why, on the one hand, the conclusion will always be framed in the context of the conversational situation (so-called global coherence (Graesser, Millis, Zwaan, 1997). On the other hand, it will have some shadows of emotionally charged personal evaluation of the processed content, and, on the third, it will merge the given linguistic and extra-linguistic inferred information, maintaining the cohesion of the inferred information. For instance, in a dialogue:

- We could talk to the manager of our local sports center and arrange a company membership.

- It sounds interesting, but it could be very expensive [Cotton, Falvey, Kent, 2002],

the utterance «It sounds interesting, but it could be very expensive» implies implicitly expressed disagreement. The keyword triggering this inference is the word but whose concept involves disagreement, a contradiction. The further conclusion builds upon processing the content of the concepts but, interesting, expensive regarding the previous context - the arrangement of the company membership in the local sports center. In this case, a theme is the proposal to get a membership, and a rheme is the details of its arrangement, while the other less significant details remain 
out of the main focus of attention and, hence, the inference (the talk with the manager, the conditions of the arrangement and so on). In other words, the comprehender focuses on the membership in a sports club, but his / her background assessment transforms from positive to the negative one - it is interesting, but expensive, unreasonable, and difficult to realize. This is an example of the principle of cohesion action (in other words, it can be called the conservation of the dominant meaning). As it is mentioned above, the conclusion is expanded on the individual, personal, emotional attitude to what has been said. The word expensive in the utterance implies that a person disagrees with the proposal, while the word interesting implies that the proposal can be further discussed. Both the inferences are inseparable in time and comprise the processed semantic content of the linguistic units included in the utterance [Yi, 2009]. Thus, they preserve the cohesion of the elements of the overall conclusion and the coherence of the conclusion itself.

One more principle of inference is the principle of information conservation. It implies that a speaker and a hearer constitute a self-contained system, within which circulating inner information remains unchanged. The principle implies that when making an inference, a comprehender processes the precise information he/ she receives from an addresser. As it has been mentioned above, inference comprises two blocks of information: a linguistic (in the course of comprehension of an utterance the semantic content of all the linguistic units is processed and then integrated into some other semantic content different from the primary one) and an extra-linguistic (it comprises all the associated information that accompanies the utterance and then can be used to understand the explicit and implicit senses the utterance contains). Regarding the huge volume of direct and indirect information that an addressee has to comprehend, the idea of processing only the precise information an addresser sends to an addressee seems to be infirm. Nevertheless, the surrounding us communication speaks for this argument with a reservation that the information we speak about is subjectively selected. Comprehending a discourse, an addresser indeed processes the precise information he Ishe receives from the addressee, but not all this information gets into inference. For instance, it is impossible to interpret the words I would have a cup of tea as a hint that the speaker wants a cup of coffee. Of course, there might be situations in which such words can be interpreted differently, but even in these cases, the principle would work in the same way. Imagine that it is a hot day, and two companions are looking for a shadowy place where they could have a rest and drink something cold. Then, one of them says: I am thirsty. The other would understand that his ther companion wants something cold to drink. Being a self-contained system within which inner information remains unchanged, they share not only linguistic information (one of the partners is thirsty) but also extra-linguistic information which involves physical and social co-presence - the day is hot, there is a chance to have a rest somewhere in a café, the trip is tiresome and causes a feeling of irritation, etc. (Graesser, Singer, \& Trabasso, 1994) and contributes to better understanding.

As a consequence, one more principle of inference becomes very important. It is a principle of mutual influence. The better the contact (mutual understanding) between an addresser and an addressee, the more efficient the information exchange will be, and, thus, the more authentic will be the inferred knowledge regarding the source. In the philosophic language, it means that in the cognitive process of crunching data, a subject assimilates himself lherself with an object of cognition to comprehend information from the latter. Thus, if cognition and the object come into a virtual contact, the latter leaves a trace on the former (Ortega y Gasset, 1980). It answers the question of why the more responsively we react to the addresser, the more precisely we comprehend what he/she says. Interlocutors influence each other leaving emotional, evaluating, even cognitive traces. Comprehending the words of our 
interlocutor, we can change our mind, or opinion on some things, we can even start seeing the world through our interlocutor's eyes. Imagine a situation when one of the interlocutors speaks about serious things with a smile, the inference will apparently be dependent on the smile of the speaker than the semantic content of the words. The same concerns the written speech. The overall tonality of speech will make a considerable impact on comprehension.

Comprehension is not only the processing of written or oral speech. It often looks like a constant addition of fleeting senses, connected with inflectional elements, agglutination of which becomes a physical aspect of the occurred mental addition (Guillaume, 1984). The contemporary study of neurochemical processes, taking place in a human brain, shows that words as arbitrary symbols are based upon topographical representations, and before being pronounced or recorded, they become audio or video images in our consciousness (Damasio, 2014). Thus, it is fundamentally impossible to consider inferences regardless of a comprehending human being, i.e., a living system, whose peculiar feature is a constant circular mutual causal interrelation "a human being - an environment." These dwellings lead to one more important principle, which could be called anthropocentric. It implies the possibility of conscious or unconscious creation of a fleeting virtual environmental image of the comprehended discourse. The image rests upon a human being's biological perception of the environment. In other words, it is an individual cognitive reflection of the environment (hidden in the discourse), which is made in parallel with the cognitive treatment of the linguistic (semantic) data. Thus, a person as a human being consciously or unconsciously reconstructs a virtual discourse environment, i.e., the temperature, time, lighting, place and the statics/dynamics of the events, letting all these into his /her subconscious and then, if these factors become important, including them in the inference (Suvorova, 2019). All the above-mentioned factors become conscious at the moment a person focuses on them, and though the factors do not belong to the linguistic block, they can make a substantial impact on the inferred knowledge. The hypothesis can find a confirmation in the works of Maturana and Varela (1987), who suppose that when communicating we do not exchange thoughts, but what we hear makes an impact on us, as a structurally determined system, and our comprehension of what has been said depends entirely on our state at the moment of comprehension [Maturana, \&Varela, 1987]. For instance, when comprehending the following passage from a literary work:

"On his bench in Madison Square Soapy moved uneasily. When wild geese honk high of nights, and when women without sealskin coats grow kind to their husbands, and when Soapy moves uneasily on his bench in the park, you may know that winter is near at hand. A dead leaf fell in Soapy's lap. That was Jack Frost's card. Jack is kind to the regular denizens of Madison Square, and gives fair warning of his annual call. At the corners of four streets he hands his pasteboard to the North Wind, footman of the mansion of All Outdoors, so that the inhabitants thereof may make ready" (Henry $O$. The cop and the anthem),

in parallel we create a mental image of the happening event. The created image reflects time (we mentally create the even in the present, in spite of the fact that when describing the event (Soapy's appearing in a park) O. Henry uses the verbs in the form of Past Simple: moved, fell, was); an open space; bad lighting (we associate a cold season with twilight); cold weather; and the statics of the happening event. This mental image does not automatically appear in the "window of our conscious," it is fleeting and can be quickly replaced by the following image in the course of the discourse enhancement, but when being focused on, it can be completely recreated in the subconscious, which speaks for its existence. The list of factors (temperature, time, lighting, place and the statics/dynamics of the above-mentioned environment), which fill in the mental image, seems to be complete, as these are the factors which 
are the physical parameters of the environment, regarding a human being's perception of it.

The next principle of inference discussed in the paper is a principle of reciprocating movement of reflection. When making an inference, our reasoning moves from integrating separate data into a single entity and then to distinguishing those details which can complement the integration. An emerging idea inductively triggers hypotheses, involving new, additional, unnoticed details, which can abruptly transform into some subsequent inferences. The previous passage from a literary work shows that when drawing an inference, the integration of all the data (both the linguistic and extra-linguistic, conscious, and unconscious ones, those belonging to semantic, physiologic, emotional, evaluative, etc. aspects of perception and comprehension) takes place. But then, in dependence on a comprehending person, some of them become included in a new inference, and some are rejected as irrelevant.

The final of the discussed principles is a principle of an analysis and synthesis circle, which partially overlaps with the previous principle of reciprocating movement of reflection. The process of analysis cannot but accompany the inference due to the nature of the inference itself. Nevertheless, the analysis that accompanies inference does not look like an ordinary rational data analysis. Its peculiar features are speed, shallowness, randomness, independence from the current premises. Primarily, it is due to the fact that any inference occurs under time pressure. Hence, the analysis is carried out quickly and superficially.

Otherwise, if a thought clings to some data, reasoning can change its direction, but will never stop. Secondly, the process of inference is constantly being enhanced by secondary emotions, as the majority of somatic markers, used in the process of making a decision, are forming in the course of education and socialization by means of connecting specific kinds of the stimulus with specific kinds of somatic states [Damasio, 2014]. Thus, the analysis, carried out irrationally, subjectively (emotions cannot belong to objective data), does not have a predictable character by nature. Thirdly, the above mentioned randomness means a lack of consistency in making inferences. Meaning is not a product of pure reasoning, and it is only a top of a conditionally discrete fragment of the contiguous and multidimensional picture of the world in all its plurality of connections and relations, the completeness of which is provided by various direct and indirect inferred knowledge or various feelings [Zalevskaya, 2005, p. 245]. The processing of such an array of diverse data cannot be carried out consistently. With the shifting of a focus of attention, the analysis starts involving precisely the data, which subjectively (consciously or unconsciously) seem to be the most relevant at these precise moments of time and analysis. In its turn, the analysis invariably turns out into synthesis, i.e., integration of the current data to make a final inference, which later on will get into the category of analyzed data in the subsequent comprehension of discourse.

\section{Materials and methods}

To verify the theoretical taxonomy of the inference principles and observe their action in discourse comprehension, the method of the associative experiment is used, firstly, because it allows tracing the way the subjects draw inferences; secondly, it provides insight into the details of the inferred knowledge; thirdly, it gives an opportunity to observe the emotional feedback from the subjects. The experiment is carried out on the material of O. Henry's novel "The Gift of Magi."

During the experiment, the first three passages taken from the novel are read with three intervals of about 10 minutes. During each interval, the subjects are to go through three stages of feedback. Firstly, they are instructed to retell what they have 
heard; secondly, they are to draw, what they have imagined while comprehending the passage; and, thirdly, they are to give short, one-word answers to the following questions:

1) Is the action in the passage you have heard static or dynamic?

2) Where does the action take place?

3) What time of the day is it: a morning, a daytime, an evening, or a night?

4) Is it cold, warm, hot, cool at the moment?

5) Is it light or dark at the place?

The subjects are not limited in time for the feedback but are instructed not to take into consideration the grammar and stylistic correctness of their retelling and to try to retell the passage right after they have heard it, without any additional reflections. The three similar stages of the experiment are necessary, on the one hand, to verify the results, on the other hand, to observe how the subjects change their view on the novel events when receiving new details with each new passage.

The passages which are read in an ordinary tempo to the subjects are the following:

1) One dollar and eighty-seven cents. That was all. She had put it aside, one cent and then another and then another, in her careful buying of meat and other food. Della counted it three times. One dollar and eighty-seven cents. And the next day would be Christmas.

There was nothing to do but fall on the bed and cry. So Della did it.

2) Della finished her crying and cleaned the marks of it from her face. She stood by the window and looked out with no interest. Tomorrow would be Christmas Day, and she had only $\$ 1.87$ with which to buy Jim a gift. She had put aside as much as she could for months, with this result. Twenty dollars a week is not much. Everything had cost more than she had expected. It always happened like that. Only \$ 1.87 to buy a gift for Jim. Her Jim. She had had many happy hours planning something nice for him. Something nearly good enough. Something almost worth the honor of belonging to Jim.

3) There was a looking-glass between the windows of the room. Perhaps you have seen the kind of looking-glass that is placed in $\$ 8$ furnished rooms. It was very narrow. A person could see only a little of himself at a time. However, if he was very thin and moved very quickly, he might be able to get a good view of himself. Della, being quite thin, had mastered this art. Suddenly she turned from the window and stood before the glass. Her eyes were shining brightly, but her face had lost its color. Quickly she pulled down her hair and let it fall to its complete length. The James Dillingham Youngs were very proud of two things that they owned. One thing was Jim's gold watch. It had once belonged to his father. And, long ago, it had belonged to his father's father. The other thing was Della's hair. If a queen had lived in the rooms near theirs, Della would have washed and dried her hair where the queen could see it. Della knew her hair was more beautiful than any queen's jewels and gifts. If a king had lived in the same house, with all his riches, Jim would have looked at his watch every time they met. Jim knew that no king had anything so valuable. So now Della's beautiful hair fell about her, shining like a falling stream of brown water. It reached below her knee. It almost made itself into a dress for her. And then she put it up on her head again, nervously and quickly. Once, she stopped for a moment and stood still while a tear or two ran down her face. She put on her old brown coat. She put on her old brown hat. With the bright light still in her eyes, she moved quickly out the door and down to the street.

The passages used in the experiment are unequal for the sake of their logical completeness. For the sake of fairness, and to avoid the interference of languages, the passages and the tasks are presented in Russian (a well-translated Russian version of the novel is used), as the subjects are native Russian speakers. 
The major target of the experiment is to trace if the drawn inferences comply with all the hypothesized principles. Due to the heterogeneity of the principles, the task for the subjects is divided into three parts. The first part of the task is focused on the action of the principles of situational economy, analogy, cohesion and coherence, reciprocating movement of reflection, and a principle of an analysis and synthesis circle. The second (graphical) part is used to trace the principles of information conservation and mutual influence. The third part is targeted at the work of the anthropocentric principle, which action is also traced in the second part of the experiment.

The subjects are a group of 8 teachers from Nosov Magnitogorsk State Technical University. The teachers are 40-64-year-old male and female associate professors, who work at different faculties: Economics, Physical training, Philosophy, and Foreign Languages. The number of the subjects is less important for the experiment, as the main focus of the experiment is on the content of the answers rather than on the statistic data of the recurrence of the subjects' answers.

\section{Results and discussion}

The analysis of the data received according to the first task "Retell the passage" (every subject is to make three retellings of three passages in total) has shown that the subjects fully process the information, making short summaries of the passages and providing their own point of view on the comprehended situation. Nevertheless, in the majority of cases, the subjects' side of the story does not fully coincide with the plan of the author. For instance, some of the subjects' summaries of the first passage are: (i) life can be really tough for the living; (ii) poverty and need make worry about every cent; (iii) one dollar and eighty-seven cents are the prices of a person's happiness. As we see, the subjects' attitude to life, personal view on various life situations makes a great impact on the summaries they make. It speaks for the assumption that when comprehending a discourse, we search for analogous situations in our mind and, in this way, focus upon those elements in the discourse which seem to be the most relevant to our analogous life experience. This hypothesis is also confirmed by an example of misconception, which can be observed in one of the subjects' retellings when comprehending the first passage - "Della tries to change the coins when buying meat and other food." As the experiment shows, the selection of the elements to be included in the inference is arbitrary, unpredictable, and inconsistent, which reflects the dynamic and changeable nature of the inference.

Further analysis of the retellings made by the subjects verifies the same results, but there is an exception. Having listened to the second and the third passages, all the subjects enlarge the volume of their retellings and start adhering more strictly to the comprehended texts. Thus, the retellings of the second passage are: (i) Della, looking at the street, is thinking what present she can buy with one dollar and eightyseven cents; (ii) Della wants to make a present for Jim, but she has only one dollar and eighty-seven cents. Nevertheless, some of the subjects continue expressing their own view on the described events, writing: "What can a person present a beloved one with a minuscule sum of money."

Regarding the maintenance of the principles of coherence and cohesion, of reciprocating movement of reflection, and a principle of an analysis and synthesis circle, their action can be traced on the dynamic changes in the chain of retellings. For instance, following the retelling of one of the subjects, we can see a consistent transformation of the feedback to the target passages. A poor girl Della has only one dollar and eighty-seven cents left before Christmas. - The money is not enough to buy a good present for Jim. - The wealth of the family is not money but Della's hair and Jim's watch. Having analyzed the first portion of information, the subject puts aside

XLinguae, Volume 13 Issue 2, April 2020, ISSN 1337-8384, ISSN 2453-711X 
some of the details belonging to the first inference and draws the next conclusion, by adding new details to those he has kept. It shows a reciprocating movement of reflection from the general to the specific and vice versa, as well as the continuity between the analysis and the synthesis which the subject makes. At the same time, the summaries maintain coherence and cohesion, which appear in the opportunity to integrate these retellings into a single one.

The second part of every task in the experiment is to draw a picture of the comprehended passage. The pictures drawn by the subjects do not differ much from each other. They are boxes decorated with ribbons; figures or a dollar sign (for instance, 1.87\$); pictures of girls; graphic depiction of tears and smiles; a mirror, etc. Thus, we can sum up that even in the graphical processing of the information, the subjects reflect the very information the author sends to them in compliance with the principle of information conservation. Even in the case of misconception, the picture has a sign of a dollar and some coins, which speaks for the above-mentioned assumption.

It is interesting that all the pictures reflect the mood the author expresses in each passage. In response to the first passage, the subjects have drawn mostly money (according to the neutral beginning of the story). Then, in the second case, the subjects have drawn presents and Christmas trees (in response to the positive words: "She had had many happy hours planning something nice for him. Something nearly good enough. Something almost worth the honor of belonging to Jim") or crying girls in response to the words: "Della finished her crying and cleaned the marks of it from her face. She stood by the window and looked out with no interest. Tomorrow would be Christmas Day, and she had only $\$ 1.87$ with which to buy Jim a gift". It should be noted that in reaction to positive or sad emotions expressed in the passage, the subjects ignore neutral information and focus on the emotional one. In response to the third passage, the subjects have drawn details pointing to movement: a ladder, a clock, a walking girl, a girl watching in a mirror, thus, reacting to the dynamics of the described events.

The third part of each task in the experiment includes answers to the questions. The subjects' answers can show whether they create a mental-physical environment relevant to the described events; what physical parameters the mental environment has; if there is any overlapping of the real environment with the cognitively processed one. The hypothesis is that if the subjects can answer these questions, then it means that a mental creation of a physical environment relevant to the discourse unconsciously occurs at the moment of this discourse comprehension. The shift in the majority of the subjects' answers to the first question "Is the action in the passage you have heard static or dynamic?" is dynamic $(\underline{5} / 3)$ - static $(\underline{6} / 2)-$ dynamic ( $6 / 2)$, which reflects the change of the events described in the passages.

The answers to the second question, "Where does the action take place?" are similar: a house or a flat.

The answer to the third question, "What time of the day is it: a morning, a daytime, an evening, or a night?" changes. After reading the first passage, the majority of answers are "an evening" (6), and in two of eight cases, it is "a day" (2). We consider this result to be either a reaction to the past form of the verbs used in the first passage and Della's having lack of time to fulfill the plans, or the interference of the real surrounding physical environment into the comprehension of the passage (the experiment took place at 4 p.m.), as, later, answering the same question to the second and the third passages, the subjects mostly change the evening time for the day time (4 out of 3 ) in both cases.

The shift in the answers to the fourth question, "Is it cold, warm, hot, cool at the moment?" is constant. In all three cases, two of eight subjects characterize the environment belonging to the discourse as cold, while the rest (6) says that it is warm. 
It is obvious, that the character of the answers is directly connected with the Christmas time, a winter, which is default cold.

In the majority of cases, the shift in the answers to the fifth question "Is it light or dark at the place?" is mostly dark $(\underline{5} / 3)$ - light $(\underline{5} / 3)$ - light $(\underline{5} / 3)$. It coincides with the shift in the answers to the third question and reflects the correction of the time of the described events - from the evening in response to the first passage to the day time in the following answers.

\section{Conclusion}

The analysis of philosophic, psychological, linguistic literature on the problem of inference has shown the necessity of studying common rules or principles, regulating the whole process of making an inference. The word "principles" implies common regulative rules which accompany the process of making an inference all along with the discourse comprehension and are consistent with its nature. In the course of study, it has become obvious that in spite the fact that inference is considered to be a form of reasoning and should be reviewed in the framework of its logic, it cannot fit within the common scientific understanding of logical principles of reasoning (the notions inference and syllogism are not equal, an inference can be only partially related to conclusions made on the basis of primary premises, as it is often drawn on the basis of arbitrary data of both linguistic and extra-linguistic character. The chosen approach to the inference phenomenon has resulted in an appeal to various spheres of human activities, and, mostly, to a comprehending human being in order to define the influence of external and internal factors on the inference process and to identify the principles that can underlie the discussed process.

The study of inference regarding the anthropocentric (biological, physiological, psychological) factors, physical (energy conservation, the change of physical parameters of the environment) and psychological laws have allowed identifying the following principles of inference: the principle of situational economy, analogy, cohesion, coherence, information conservation, mutual influence, an anthropocentric principle, a principle of reciprocating movement of reflection and a principle of an analysis and synthesis circle. The studied principles do not only reveal the nature of inference but point to the mechanisms of its action. The associative experiment has fully verified the above mentioned principles. An interesting assumption has been made regarding the anthropocentric principle of inference. When comprehending a discourse, a person can borrow physical parameters of the real environment to create a mental environment relevant to the described events. The practical use of the received results can be found in any sphere of intellectual work, beginning with marketing companies and finishing with the creation of artificial intelligence.

\section{Bibliographic references}

ARISTOTEL. 1984. Works: in 4 volumes. Moscow: Idea, vol. 4. Available online: https://platona.net/load/knigi_po_filosofii/istorija_antichnaja/aristotel_sochinenija_v_ chetyrekh_tomakh_tom_1_red_v_f_asmus/7-1-0-389

ASMUS, V. F. 1998. Ancient philosophy. Moscow: High school. Available online: http://www.logic-

books.info/sites/default/files/asmus._antichnaya_filosofiya_1999.pdf.

BICKERTON, D. 1995. Language and human behavior. Seattle: University of Washington Press. Available online: https://www.researchgate.net/publication/270955877_Language_and_human_behavio r_Derek_Bickerton_Seattle_University_of_Washington_Press_1995_Pp_180. 
COTTON, D. - Falvey, D., - Kent, S. 2002. Market leader: pre-intermediate Business English course book. Pearson Longman. Available online: https://www.amazon.com/Market-Leader-Pre-Intermediate-Course-

Book/dp/0582507200.

DAMASIO, A. 2014. Descartes' error. Emotion, Reason and the Human Brain. New York: Penguin Group. Available online: https://ahandfulofleaves.files.wordpress.com/2013/07/descartes-error_antoniodamasio.pdf.

DEWEY, J. 1933. How we think. Boston New York Chicago: D. C. Heath \& Co. Publishers. Available online: https://archive.org/details/howwethink000838mbp/page/n8.

Dictionary of foreign words. 1989. Moscow: Russian language.

EMETS, T.V. - BARYSHNIKOVA, I. V. - TRUTNEV, A. Y. - SUVOROVA, E.V. - ACHMETZYANOVA, T. L. 2018. Logical and linguistic strategies for translating complex sentences in literary texts of natural languages XLinguae, vol. 11, n. 2, pp. 316. Available online: http://www.xlinguae.eu/files/XLinguae2_2018_1.pdf.

FAUCONNIER, G. - TURNER, M. 2002. The way we think: conceptual blending and the mind's hidden complexities. New York: Basic Groups. Available online: https://tecfa.unige.ch/tecfa/maltt/cofor-1/textes/Fauconnier-Turner03.pdf.

GUILLAUME, G. 1984. Foundations for a Science of Language. Amsterdam, Philadelphia: John Benjamins. Available https://benjamins.com/catalog/cilt.31.

GRAESSER, A. - MILLIS, K. - ZWAAN, R. 1997. Discourse comprehension. Annual review of psychology, vol. 48, n. 3, pp. 163-189. Available online: https://www.annualreviews.org/doi/abs/10.1146/annurev.psych.48.1.163.

GRAESSER, A. - SINGER, M. - TRABASSO T. 1994. Constructing inferences during narrative text comprehension. Psychological review, vol. 101, n. 3, pp. 371395. online: https://pdfs.semanticscholar.org/6d18/5f5cfc7e1df9105459a68e96f82fbb047f52.pdf. KOROTKOV, E. A. 2011. Logic: training manual for law students. Belgorod: IPK NIU «BelSU».

LAKOFF, G. - JOHNSON, M. 2008. Metaphors we live by. University of Chicago Press. Available online: http://shu.bg/tadmin/upload/storage/161.pdf.

MAKAROV, M. L. 2003. Discourse theory. Moscow: ITDGK «Gnosis». Available online: http://yanko.lib.ru/books/cultur/makarov-osnovu_teorii_diskursa-81.pdf.

MATURANA, H. R. - VARELA, F. J. 1987. The tree of knowledge: The biological roots of human understanding. Boston: Shambhala Publications. Available online: https://www.cybertech-engineering.ch/research/references/Maturana1988/maturana-h1987-tree-of-knowledge-bkmrk.pdf.

ODINTSOVA, I. V. 2016. Implicature and inference in lingvo-didactics. MIRS, 4. URL: Available online: https://cyberleninka.ru/article/n/implikatsiya-i-inferentsiya-vlingvodidaktike.

ORTEGA Y GASSET, X. 1980. Two great metaphors. In: Theory of metaphor.

Moscow: Progress. Available online: http://www.lib.ru/FILOSOF/ORTEGA/ortega11.txt.

Oxford advanced learner's dictionary of current English. 2005. Oxford University Press.

Philosophical dictionary. 1981. Moscow: Politpublishing.

Philosophical writings of Descartes. 2012. Cambridge University Press. DOI: Available online: http://doi.org./10.1017/CBO09780511805042.

Philosophical writings by Immanuel Kant (1997) Bloomsbury Academic. Available online: https://www.bloomsbury.com/uk/philosophical-writings-immanuel-kant9780826402998/. 
RICKHEIT, G. - STROHNER, H. 1985. Inferences in text processing. North Holland- Amsterdam - New York - Oxford.

SUVOROVA, E. V. Inference: principle of anthropocentrism in narrative discourse perception. Philological sciences. Questions of theory and practice, vol. 12, n. 5, pp. 249-252. Available online: https://cyberleninka.ru/article/n/inferentsiya-printsipantropotsentrizma-pri-vospriyatii-narrativnogo-diskursa.

SUVOROVA, E. V. - POLYAKOVA, L. S. 2018. Double inference in the processes of comprehension of Russian and English discourse complicated by an idiom. 3L: Language, Linguistics, Literature, vol. 24, n. 2, pp. 43-57. Available online: http://ejournals.ukm.my/31/article/view/20492.

VYGOTSKEY, L. S. 2019. Thought and Speech. Moscow: National education press. YI, T. H. 2009. From meaning to inference: Exploring the Semantics-Pragmatics Interface through Online Processing and Development. Dissertation. Department of psychology. Harvard University Graduate School of Arts and Sciences.

Available

online: https://pdfs.semanticscholar.org/535d/e2b01ed221a57a687584fe2680956bcf1604.pdf. ZALEVSKAYA, A. A. 2005. Psycho-linguistic researches. Word. Text: Selected papers. Moscow: Gnosis. Available online: https://www.klex.ru/37d.

ZAVARZINA, S. A. 2016. On defining the role of inference in the system of text categories. Bulletin of the SUSU. Series "Linguistics", vol. 13, n. 1. Available online: https://vestbik.susu.ru/linguistics/article/view/4772.

Words: 8106

Characters: 53116 (29,51 standard pages)

Elena Suvorova

Department of Foreign Languages for Engineering

Nosov Magnitogorsk State Technical University

Russia

suvorlen@yandex.ru 